\title{
O SIGNIFICADO PSICOLÓGICO DE PALÃVRĀS RELACIONADAS A VALORES ESPIRITUAIS ENTRE ESTUDANTES DE ENFERMAGEM
}

\author{
Célia Pires de Araújo * \\ Wanda de Aguiar Horta **
}

$\mathrm{RBEn} / 11$

ARAÚJO, C.P. e colaboradora - O significado psicológico de palavras relacionadas a valore: espirituais entre estudantes de enfermagem. Rev. Bras. Enf.; DF, 31 : 93-100, 1978.

A enfermagem tem como funçāo específica assistir o ser humano (individuo, família, comunidade) no atendimento de suas necessidades bio-psicosócio-espirituais e torná-lo independente desta assistência pelo ensino do autocuidado. A cada dia a literatura de enfermagem por meio de pesquisas publicadas está apresentando novas contribuiçōes ao conhecimento e assistência das necessidades do paciente nos aspectos biológicos, psicológicos e sociais. Entretanto, muito pouco tem sido realizado em termos das necessidades espirituais.

Com os artigos de GODOY (1962), MAKAREM (1965), HALPERN (1966), BERKOWITZ (1967), FARR (1968), COOREVITS (1968), PIEPGRAS (1968), BROOKES (1969), BERNS (1971) e NICOLODI
(1973) percebe-se a confirmaçāo da necessidade religiosa no ser humano, e a preocupação que os autores possuiam em incluir uma assistência a essa necessidade.

Recentemente os estudos realizados com pacientes por GELAIN (1974) $\theta$ ARAÚJO (1976), parecem comprovar que essa necessidade é efetiva para a maioria dos pacientes hospitalizados e por eles verbalizadas, incluindo aspectos de como gostariam que a enfermagem os assistisse em suas carências espirituais.

Por outro lado, nâo temos elemento para afirmar que a enfermagem hospitalar e em particular, o enfermeiro, está atendendo a esta necessidade básica em seus aspectos quantitativo e qualitativo. Observa-se, porém, que na prática da enfermagem a assistência à essa neces-

* Docente da Escola de Enfermagem USP. Mestre em Enfermagem

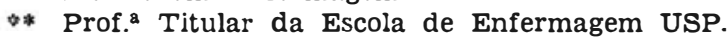


ARAÚJO, C.P. e colabiradora - O significado psicológico de palavras relacionadas a valores espirituais entre estudantes de enfermagem. Rev. Bras. Enf.; DF, 31 : 93-100, 1978.

sidade parece ser negligenciada por parte dos profissionais.

Estaria a principal causa desta aparente irrelevância da assistência das necessidades espirituais do paciente relacionada com a formação profissional ou àquela anterior à sua entrada na Universidade?

Tentando encontrar resposta a esta indagação, nos propusemos a estudar e verificar se o probelma está relacionado com as causas já citadas num estudo longitudinal em duas fases:

a) alunos ingressantes no tronco profissional;

b) a mesma população na última fase do ciclo profissional.

Nessa primeira fase, nos propusemos a averiguar qual o significado psicológico para os estudantes ingressantes nas Escolas de Enfermagem das palavras que estão diretamente relacionadas com a esfera religiosa, desde que se considera "signifícado psicológico" e comportamento verbal, resultante das contingências sociais às quais o individuo está sujeito.

\section{METODOLOGIA}

A populaçāo constituiu-se de estudantes de enfermagem matriculados no primeiro semestre de ciclo profissional, pertencentes às quatro Escolas de Enfermagem da capital de São Paulo, que por ordem cronológica na coleta de dados receberam a denominação operacional de A, B, C, e D. Com exceção de cinco alunos que estavam matriculados mas não freqüentaram as aulas durante a semana em que os dados foram obtidos, os demais estudantes somavam o total de 246, e todos eles fizeram parte do estudo.

Pela TABELA I pode-se verificar algumas características da população em apreço, segundo cada Escola.
Para a coleta de dados utilizou-se a Escala cio Diferencial Semântico de Osgood simplificada para o Brasil, sob a forma de um caderno contendo as seguintes palavras: Alma, Corpo, Morte, Saúde, Deus, Médico, Dor, Hospital, Religiāo, Prece, Enfermeira, Vida, Sacerdote, Doença. Para o propósito deste estudo porém, nos limitamos a apresentar resultados do significado psicológico das palavras: Alma, Corpo, Morte, Deus, Religiāo, Prece, Vida e Sacerdote.

Todas as Escolas foram visitadas por ocasiāo da primeira semana de aulas do semestre letivo de 1977. Após consentimento prévio da Administraço, foi dada explicação conjunta aos alunos de cada Escola de maneira pela qual o caderno deveria ser preenchido.

Os resultados obtidos foram computadorizados em termos de levantamento dos dados e tratamento estatístico para média e desvio padrāo. Foi aplicado o teste "t" de Student para estudo de significância, estabelecendo-se o nível de 5\%. Para análise da estereotipia aplicou-se $o$ indice de Contradição Interna (C. I.), obtido pela diferença da somatória dos valores absolutos e algébricos, atribuídos em cada escala, dividido pelo número de sujeitos, em cada fator. Quando a diferença se aproxima ou é igual a zero, as respostas são consideradas estereotipadas, ou seja, todas obedecem a mesma direção. Os índices depois de tabulados segundo sua freqüência, foram distribuidos em quartis. Os valores contidos no primeiro quartil: abaixo de $0, \epsilon$. foram considerados índices de estereotipia e os contidos no quartil 4, acima de 1,8 foram considerados indices de elevada Contradiçāo Interna.

\section{RESULTADOS}

Os resultados serão apresentados como segue: 1) Análise das médias; 2) Nível de significância a $5 \%$ pela aplicação do 
ARAÚJO, C.P. e colabıradora - O significado psicológico de palavras relacionadas a valores espirituais entre estudantes de enfermagem. Rev. Bras. Enf.; DF, 31 : 93-100, 1978.

" $t$ " de Student; 3) fndice de Contradição Interna.

1) Foram encontrados os seguintes resultados na análise das saídas:

- Quanto ao Fator I, valorativo, os estudantes consideraram a Alma, Corpo, Deus, Religião, Prece, Vida e Sacerdote como saudáveis, maravilhosos, bons, desejáveis e a Morte como doentia, horrível, indesejável e má.

- Quanto ao Fator II, potência, a população estudada considerou Alma, Corpor, Deus, Religiāo, Prece, Vida, Sacer- dote e Morte como grandes, pesados, altos e intensos.

- Quanto ao Fator III, atividade, os estudantes consideraram Corpo, Deus, Religiāo, Prece, Vida e Sacerdote como ativos, rápidos, barulhentos e mortais. Quanto às palavras Alma e Morte três grupos as consideraram passivas, lentas, silenciosas e imortais e um grupo a: consideraram ativas, rápidas, barulhentas e mortais.

2) Encontramos no QUADRO I os resutlados quanto a significância do "t" de Student ao nível de $5 \%$.

QUADRO I

RESULTADOS QUANTO A SIGNIFICANCIA APÓS APLICAÇĀO DO “t” DE STUDENT AO NIVEL DE $5 \%$.

PALAVRA

ALMA

CORPO

MORTE

DEUS
FATORES

II - Potência

ESCOLAS

C $>$ D

III - Atividade

$A>B$

$A>D$

C $>$ D

$\mathrm{B}>\mathrm{C}$

$\mathrm{B}>\mathrm{D}$

III - Atividade $\mathrm{D}>\mathrm{B}$

II - Potência

A $>$ B

III - Atividade

$B>A$

$\mathrm{B}>\mathrm{C}$

$B>D$

I - Valorativo $\mathrm{B}>\mathrm{A}$

C $>A$

$D>A$

$\mathrm{B}>\mathrm{D}$
INTERPRETAÇAO DOS RESULTADOS

A Escola C considerou a Alma mais pesada, grande, alta e intensa.

As Escolas A e C consideraram a Alma mais ,passiva, lenta silenciosa e imortal.

A Escola B considerou a Alma mais ativa, rápida, barulhenta e mortal.

A Escola D considerou o Corpo mais ativo, rápido, barulhento e mortal.

A Escola A considerou a Morte mais pesada, grande, alta $\mathrm{e}$ intensa.

A Escola B considerou a Morte mais ativa, rápida, barulhenta e mortal.

As Escolas B, C e D em relação à escola A consideraram Deus mais saudável, maravilho, desejável e bom. O mesmo ocorreu na escola B quanto à $\mathrm{D}$. 
ARAÚJO, C.P. e colaboradora - O significado psicclógico de palavras relacionadas a valores espirituais entre estudantes de enfermagem. Rev. Bras. Enf.; DF, 31 : 93-100, 1978.

RELIGIAO

PRECE

VIDA

SACERDOTE

$$
\begin{array}{ll}
\text { II - Potência } & \text { B }>\text { A } \\
& \text { B }>\text { C }
\end{array}
$$

$$
\begin{array}{ll}
\text { III - Atividade } & A>B \\
& A>D
\end{array}
$$

I - Valorativo $\mathbf{B}>\mathbf{A}$

C $>A$

$\mathrm{D}>\mathrm{A}$

$B>C$

$\mathrm{B}>\mathrm{D}$

II - Potência
$\mathrm{B}>\mathrm{A}$
$\mathrm{B}>\mathrm{C}$
B $>$ D

I - Valorativo $\mathrm{B}>\mathrm{A}$

C $>\mathrm{A}$

$\mathrm{D}>\mathrm{A}$

$B>D$

II - Potência

$$
\begin{aligned}
& B>A \\
& D>A \\
& B>C
\end{aligned}
$$

A Escola B considerou Detus mais pesado, grande, alto $\mathrm{e}$ intenso.

A Escola A considerou Deus mais passivo, lento, silencioso e imortal.

As Escolas B, C e D em relação à escola $\mathrm{A}$ consideraram a Religiāo mais saudável, maravilhosa, desejável e boa; o mesmo ocorrendo com a escola $B$ em relação às escolas $C$ e $D$.

A Escola B considerou a Religião mais pesada, grande, alta' e intensa.

As Escolas B, C e D em relação à Escola A consideraram a Prece mais saudável, maravilhas, desejável e boa. $O$ mesmo ocorrendo em relação entre as escolas B e D.

As Escolas B e D em relação à A consideraram a Prece mais mais pesada, grande alta e intensa; o mesmo ocorrendo en: tre as escolas B e C.

I - Valorativo

$\mathrm{B}>\mathrm{A}$

As Escolas B, C e D em relaC $>A$ ção à escolä A consideraram o D $>$ A Sacerdote mais saudável, maB $>$ D ravilhoso, desejável e bom, 0 mesmo ocorrendo entre as escolas B e D.

II - Potência

$$
\text { B }>\text { A }
$$

As Escolas B e D considera-

$\mathrm{D}>\mathrm{A}$

III - Atividade ram o Sacerdote mais pesado grande, alto e intenso.

As Escolas B e C em relaçāo à Escola A, consideraram 0 Sacerdote mais ativo, rápido, barulhento e mortal; ocorrendo a mesma situação entre a Escola B e D. 
ARAÚJO, C.P. e colaboradora - O significado psicológico de palavras relacionadas a valores espirituais entre estudantes de enfermagem. Rev. Bras. Enf.; DF, 31 : 93-100, 1978.

\section{QUADRO II}

RESUMO DOS RESULTADOS DE “t” DE STUDENT AO NIVEL DE 5\% QUANTO AOS FATORES.

FATO

I - Valorativo

II - Potência

III - Atividade

\section{PALAVRAS}

Deus, Religiāo, Prece e

Sacerdote
Religiāo

Deus, Religiāo, Prece

Religiāo

Prece

Sacerdote

Alma

Morte

Alma e Deus
Alma e Morte
Morte
Alma
Corpo
Sacerdote

$$
\begin{aligned}
& \mathrm{B}>\mathrm{A} \text { e } \mathrm{D} ; \mathrm{C}>\mathrm{A} ; \mathrm{D}>\mathrm{A} \\
& \text { B }>\text { C } \\
& \mathrm{B}>\mathrm{A} \text { e } \mathrm{C} \\
& \mathrm{B}>\mathrm{D} \\
& \mathrm{D}>\mathrm{A} \\
& B \text { e } D>A \\
& C>D \\
& \mathrm{~A}>\mathrm{B} \\
& \mathrm{A}>\mathrm{B} \text { e D } \\
& B>C \text { e } D \\
& \mathrm{~B}>\mathrm{A} \\
& C>D \\
& \mathrm{D}>\mathrm{C} \\
& \mathrm{B}>\mathrm{A} \text { e } \mathrm{D} ; \mathrm{C}>\mathrm{A}
\end{aligned}
$$

3) A análise do índice de Contradição Interna revelou os seguintes resultados:

A populaçāo das Escolas A, B, C e D no fator I (Valorativo) quanto às palavras Alma, Corpo, Deus, Religiāo, Prece, Vida, Sacerdote, acusaram estereotipia, em vinte e um (21) casos o indice foi igual a zero (0).

Quanto à palavra Morte no mesmo fator toda a populaçāo revelou alto indice de C.I., acima de 1.8 até 2,39.

No Fator II (Potência), toda a populaçāo, em todas as palavras situou-se no primeiro quartil, indicando tendência a estereotipia.

No fator III (Atividade), em relaçāo às palavras Corpo, Morte, Vida e Sacerdote, toda a populaçāo situou-se no primeiro quartil, indicando estereotipia. Nas Escolas A, B e D esta estereotipia estendeu-se à palavra Deus; nas Escolas A e $\mathbf{C}$ incluiu no primeiro quartil a palavra Religiāo e também houve estereotipia nas Escolas A e D em relação à palavra Alma.

As demais palavras situaram-se entre o $2^{\circ}$ e $3^{\circ}$ quartís indicando discreta tendência para Contradição Interna.

\section{DISCUSSAOO}

Neste primeiro estudo observamos que de uma maneira geral os estudantes ingressantes no tronco profissional das Escolas de Enfermagem, tem comportamentos verbais, isto é, significados psicológicos, tendendo para a estereotipia em quase todas as palavras relacionadas a valores religiosos, principalmente quanto aos fatores Valorativo e Potência, com exceção da palavra Morte, que gerou alto indice de Contradição Interna.

A Morte está ligada nāo somente aos valores religiosos e espirituais mas à própria sobrevivência, em seu significado psicológico entram múltiplos valores 
ARAÚJO, C.P. e colaboradora - O significado psicológico de palavras relacionadas a valores espirituais entre estudantes de enfermagem. Rev. Bras. Enf.; DF, 31 : 93-100, 1978.

conflitantes provocando o resultado encontrado.

Na população estudada (Tabela I) há individuos com 35 e 43 anos, constituindo uma minoria, a maioria é de jovens que até o momento, presumimos, pelas suas próprias características psicológicas, nāo refletiram em profundidade sobre a Morte e todas as suas implicações - a sua própria morte, a doentes queridos. Após o Curso de Enfermagem enfrentando diariamente 0 binômio Vida-Morte, apresentam ainda este alto indice de Contradição Interna?

Quanto ao fator III (Atividade) a estereotipia manteve-se em toda a população nas palavras Corpo, Morte, Vida, Sacerdote. Pequenas diferenças que não chegaram a alcançar altos indices de C.I., mantendo ora estereotipia ora tendência para Contradição Interna, nas outras palavras.

Das quatro Escolas em estudo salientou-se a Escola B, já nas médias em relaçāo ao fator Atividade nas palavras Alma e Morte opondo-se frontalmente ao significado psicológico atribuido pelos estudantes das outras Escolas, estes resultados foram significante segundo o " $t$ " de student ao nível de $5 \%$. E ainda a popuiação da Escola $B$ quem mais polariza seus conceitos, comprovado pelo teste " $t$ " com valores significantes em 24 análises, nos três fatores, sendo que a maior incidência ocorreu no fator valorativo (9) nas palavras Deus, Religiāo, Prece e Sacerdote.

A população das Escolas $C$ e $D$ cada um com sete " $t$ " significantes principalmente no fator valorativo. A população da Escola só polarizou cinco vezes em três palavras: Alma, Morte e Deus, nos fatores Potência e Atividade.

Na palavra Vida nāo houve significância, qual teria sido a razāo desta harmonia, em termos de significado psicológico, entre a populaçāo. Seria de esperar que os jovens apresentassem alto indice de Contradição Interna, diante de palavra tão significativa em termos de valores humanísticos, não só religiosos.

Resta-nos perguntar quais as causas que levaram a uma diferença tão acentuada do significado psicológico dos estudantes da Escola B? Reportemo-nos à tabela I, a população é constituída de 57 alunos, inclui estudantes até 43 anos, em minoria, enquanto nas Escolas A, C e $\mathrm{D}$ a idade máxima é de 30 e 35 anos. E a Escola $B$ que tem maior número de estudantes procedentes de outros locais fora de São Paulo (17). Nas Escolas A. C e D a maioria é católica enquanto na Escola B, $77 \%$ da população é protestante. Seriam estes fatores responsáveis pelo comportamento verbal desta população? Ou só o fator religião, é o elemento ou variável preponderante e responsável pelo "significado psicológico" atribuido pela população às palavras relacionadas aos valores espirituais? Mas, e nas outras Escolas, onde a maioria é católica? Este resultado implica em estudos culturais e religiosos, que no momento, nesta fase inicial do trabalho não nos cabe aprofundar, mas sim estudar profundamente o assunto, empreender novas pesquisas, usar outras abordagens que nos levem ao caminho da verdade.

\section{CONCLUSAOO}

Os resultados obtidos na primeira fase deste estudo evolutivo, em uma populaçāo de 246 estudantes recém-ingressantes no tronco profissional de quatro Escolas de Enfermagem da cidade de São Paulo leva-nos às seguintes conclusões:

1) Os estudantes ingressantes trazem consigo comportamentos verbais estereotipados constatados pelo significado psicológico atribuídos às palavras rela- 
ARAƯJO, C.P. e colaboradora - O significado psicológico de palavras relacionadas a valores espirituais entre estudantes de enfermagem. Rev. Bras. Enf.; DF, 31 : 93-100, 1978.

cionadas aos valores espirituais: Alma, Corpo, Deus, Religião, Prece, Vida, Sacerdote, quanto aos fatores Potência e Atividade. Quanto ao fator Valorativo, com exceção da palavra Morte, os demais são valores que obedecem a mesma direçāo (estereotipia). Quanto à palavra Morte, no fator Valorativo houve alto indice de Contradição Interna.

\section{REFERENCIAS}

ARAUJO, C. P. - A problemática a assistência religiosa em enfermagem. Rev. Esc. Enf. USP. 9 , (1): 27-34, 1975.

ARAUJO, C. P. - Estudo sobre a necessidade religiosa de pacientes em face pré-cirúrgica. Dissertaçāo de Mestrado apresentada à Escola de Enfermagem da USP, 6 de outubro de 1976.

BERKOWITZ, P. - The jewish patient in hospital. Am. J. of Nurs. 67 (11) : 2335, Nov. 1967.

RERNS, A. - Ministering to religious needs is important part of care. Mod Nurs. Mome, 26 : 4, Apr., 1971.

BROOKES, J. - Care of the whole person. New Zeal Nurs. J., 62 : 7-8, Mar. 1969

COOREVITS, S. - Meeting the spiritual needs of our patients. S. Jamaican Nurse, 8 : 37, Sep. 1968.

FARR, A. D. - Blond transfusion and religion. Nursing Mirror, $12 \gamma$ (1) : 28, 1968.

GELAIN, I. - Necessidade psico-social do paciente. Rev. Bras. Enf. 27 : 3, julset., 1974.

GODOY, F. - Necessidade religiosa do paciente israelita hospitalizado. Rev. Bras. Enf. 15 (5) : 410, out. 1962.

HALPERN, M. - The nurse and the jewish patient. Canadian Nurse, 62 (7): 19, jul. 1966.
2) A variável religiāo parece ser um fator importante no significado psícológico atribuido às palavras relacionadas aos valores religiosos, uma vez que a Escola B com $77 \%$ de sua população é constituída de protestantes, salientouse significativamente ao nivel de $5 \%$ das demais Escolas, polarizando seu comportamento verbal.

\section{BIBLIOGRAFICAS}

HORTA, W. A. - Enfermagem: teoria, conceitos, princípios e processo. Rev. Esc. Enf. USP. 8 (1) : 7-15, 1974.

LANE, S. T. M. \& HORTA, W. A. - Significado psicológico de saúde oomo função de contingências grupais em duas faculdades de Sāo Paulo. Rev. Esc. Enf. USP, 10 (1) : 15-56, abril, 1976.

LANE, S. T. M. - Significado psicológico de palavras em diferentes grupos sócio-culturais. Revista de Psicologia Normal e Patológica. XVIII (3 e 4) : 3152, julho-dezembro, 1972.

MAKAREM, A. V. - Assistência religiosa dos doentes hospitalizados. Rev. P. Hosp. 13 (5) : 37, maio, 1965.

NICOLODI, E. - Assistência espiritual no hospital. Rev. P. Hosp. 21 (1) : 29-34, jan. 1973.

OSGOOD, C. E. - The measurement of meaning. Urbana, University of Illirsois, PRESS, 1957.

OSGOOD, C. E. - Exploration in semantic space: a personal diary. Journal of 80cial Isseus, 27 (4): 5-64, 1971.

PIEPGRAS, R. - The other dimension: spiritual help. Amer. J. Nurs. 68 : 2610-3, Dec. 1968. 


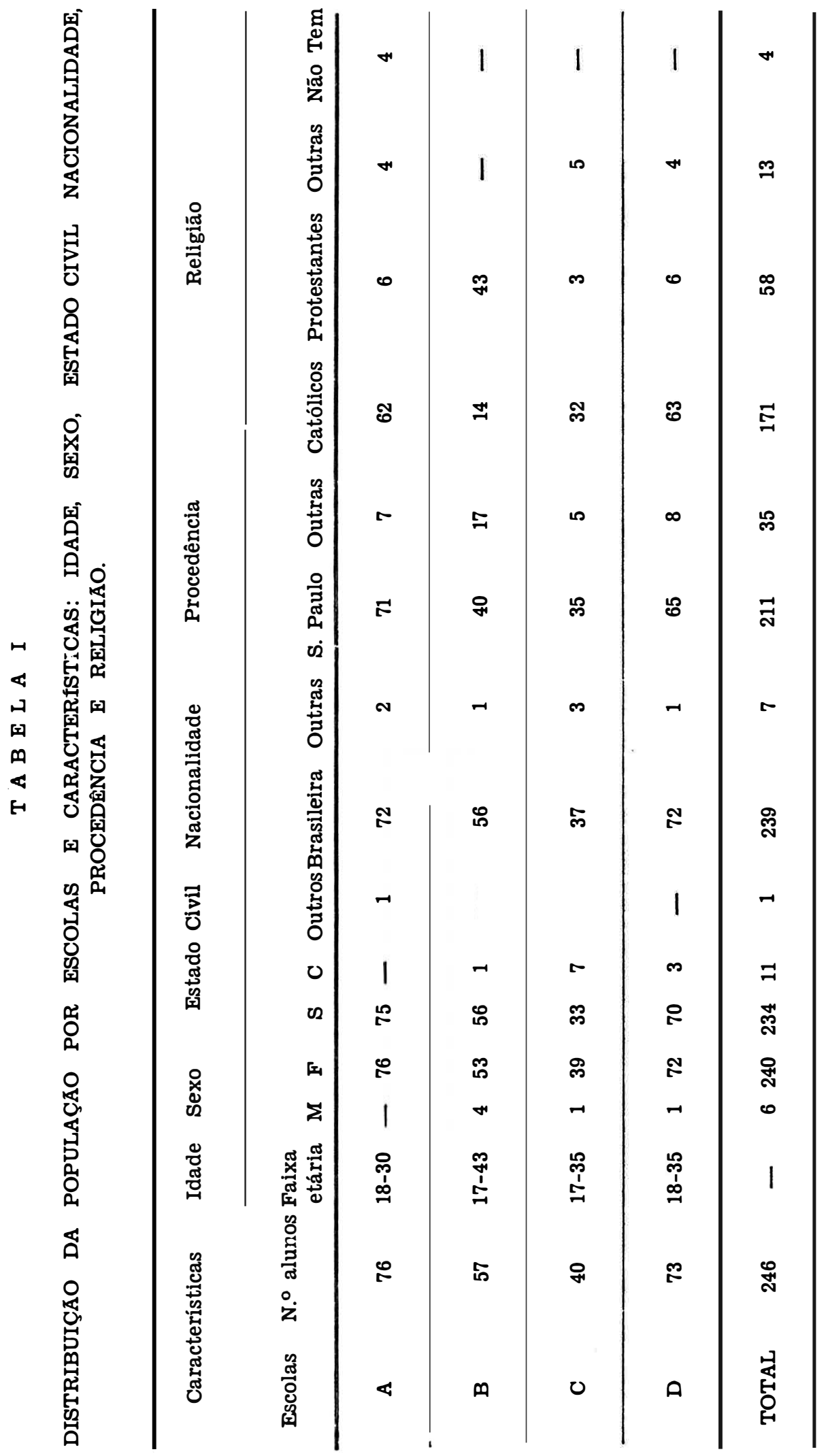

